\title{
VRT in Traumatic Maxillo-Facial Injuries; Is it of an Added Value Compared to Axial and Reconstructed CT Images?
}

\author{
HANY EL-ASSALY, M.D. \\ The Department of Diagnostic and Interventional Radiology, Faculty of Medicine, Cairo University
}

\begin{abstract}
Background: Maxillo-facial fractures are very frequently seen as a result of increased incidence of road traffic accidents and aggressive fights. Due to new advances in multi-slice computed tomography and 3D VRT reconstructed images, accurateness of detection of occult fractures and outcome of maxilla-facial traumas has noticeably improved.
\end{abstract}

Aim of Study: This study was conducted aiming at the description of different forms of maxillo-facial injuries, imaging criteria of different fractures of the maxilla and facial bones as well as the benefit of utilizing 3D VRT computed tomography with image reconstruction compared to axial CT images.

Patients and Methods: Prospective study of 100 patients, coming to the Emergency Department with trauma and clinical evidence suggestive of maxillo-facial injuries. Multi-slice CT was done to all patients with coronal and sagittal as well as VRT reconstruction. All studies were assessed for presence of maxillo-facial fractures with detection of the types and extent of these fractures as well as associated soft tissue injuries. The findings missed or confirmed by the VRT image compared to those found by the axial images were assessed.

Results: We detected that maxillo-facial fractures were more common in males $(90 \%)$ than in females $(10 \%)$. Road traffic accidents came first regarding the cause of these injuries followed by physical attack and fall from a height. The age group most affected was ranging from 18-35 years in 37\% of the cases.

Commonest fractures were seen at the maxillary sinuses (in $43 \%$ of the cases) followed by the nasal bones, zygomatic arches, mandible and orbital bony boundaries. Associated soft tissue injuries were very common. The extension of the complex fractures, occult fractures and bony displacements were more precisely assessed. VRT was superior to axial image in detection of fractures with others missed compared to the findings by the axial CT images.

Conclusion: Multi-slice computed tomography offers excellent resolution needed for proper assessment of facial bones' difficult anatomy hence helping in the accurate assessment of facial bones' fractures needed for proper planning for surgery with VRT images adding more data compared to the axial and reconstructed images.

Correspondence to: Dr. Hany El-Assaly, E-Mail: hanyelassaly@gmail.com
Key Words: VRT - Computed tomography - Fractures Maxillo -facial - RTA.

\section{Introduction}

MAXILLO-FACIAL injuries are extremely widespread in patients with isolated trauma or polytrauma patients [1]. Facial fractures are the cause of a huge number of Emergency Department visits with increased risk of morbidity and mortality due to multiple injuries to facial bony and soft tissue structures as well as associated complications and injuries affecting other parts of the body [2].

The new advances in the technology of imaging as well as therapy led to better patients' outcomes. The assessment of maxillary and facial regions is difficult owing to the complex anatomical structures and is more difficult in traumatic patients [3].

MDCT evolved as the imaging modality of choice in evaluating the patients of maxillofacial trauma [4]. Fractures' extents, fragments' displacements and soft tissue injuries are adequately and precisely diagnosed by MDCT helping in detecting the exact injuries in much less time [5].

Multi-Planar Reformations (MPR) in addition to 3D VRT images allowed accurate diagnosis and precise planning for surgery as they give a more overall image of the configuration of the injured structures thus providing outstanding information

\footnotetext{
List of Abbreviations:

MSCT : Multi-Slice Computed Tomography.

MDCT : Multi-Detector Computed Tomography.

3D : Three Dimensions.

RTA : Road Traffic Accident.

MPR : Maximum Intensity Projection.

VRT : Volume Rendering Technique.

SAH : Sub-Arachnoid Hemorrhage.

SDH : Sub-Dural Hemorrhage.

EDH : Epi-Dural Hemorrhage.
} 
about comminuted fractures as well as bone displacements [6] thus helping in surgical management $[7,8]$.

The aim of our work is to discuss the role of MDCT and 3D VRT studies in assessment of maxillo-facial injuries with the added value of 3D VRT images from axial CT images in cases with maxillofacial injuries.

\section{Patients and Methods}

\section{Patients:}

The study was approved by the Ethical Committee of Kasr Al-Aini Hospitals (Cairo University), and an informed consent was obtained assuring respect of the confidentiality of the medical records. The study design is prospective study. This study included assessment of 100 cases, their age ranged from 18-65 years over a period of three years (from September 2016 till April 2019) who were prospectively recruited for this study. All patients were post-traumatic refered from the Emergency Department of Kasr Al-Aini Hospitals (Cairo University) with clinical evidence of maxillo-facial fractures.

\section{Methods:}

\section{Technique of MDCT:}

CT studies were performed by Toshiba Aquilion 64-Slice CT scanner (made in Japan).

MDCT with volumetric acquisition was done in axial planes from upper border of frontal sinus to chin using standard CT protocol. From axial images thin sections $(1.25 \mathrm{~mm})$ were made through inbuilt software followed by Multi-Planar Reconstructions (MPR) in coronal and sagittal planes along with 3D VRT reconstruction.

\section{Data analysis:}

Frontal bones fractures were classified according to Manolidis into types $\mathrm{I}-\mathrm{V}$ as follows [8] :

- Type I: Anterior wall fracture with minimal communication.

- Type II: Comminuted anterior wall fracture with extensions to nearby bones.

- Type III: Non-displaced anterior and posterior wall fractures.

- Type IV: Anterior and posterior wall fractures with dural injury.

- Type V: Like type IV with anterior cranial fossa disruption.

The assessment of the rest of the fractured bones was based on the walls affected, degree of comminution and associated soft tissue injuries while complex fractures were classified according to Le fort system into types I-III [8] .

Data obtained from axial and reformatted images were compared to 3D VRT images findings and given a score out of 3 as follows:

1- 3D gave less data than axial and reformatted images.

2- 3D gave similar data to axial and reformatted images.

3- 3D gave more information than axial and reformatted images.

Descriptive analysis was done to generate frequency tables for various types of maxillo-facial injuries.

\section{Results}

The most common cause of injury was RTA in 85 patients (85\% of cases) with the second most common cause was fall from height in 10 cases $(10 \%)$ then physical assault in 5 cases $(5 \%)$. Males were found to be of higher affection regarding maxillo-facial fractures (90 cases) accounting for $90 \%$ of cases compared to only $10 \%$ in females (10 case).

The most common fractures in this study were seen in the maxillary sinus walls found in 43 cases ( $43 \%$ of cases) followed by nasal bones and zygomatic bones fractures in 14 cases each (both accounting for $28 \%$ of the cases). Next were the fractures of the mandibular bones and orbital bony boundaries found in 26 cases (26\%). According to frequency of fractures, frontal bone was the most commonly ( 15 cases accounting for $15 \%$ ), followed by temporal, parietal, occipital and sphenoid bones while pterygoid fractures were found in 6 cases (6\% of cases) Fig. (1) and (Table 1).

Table (1): Classification of cases according to type of fractures.

\begin{tabular}{lc}
\hline Type of fracture & Number of cases \\
\hline Maxilla & 43 \\
Zygomatic bone & 14 \\
Nasal bone & 14 \\
Mandible & 11 \\
Orbital bones & 15 \\
Frontal bone & 15 \\
Temporal bone & 11 \\
Sphenoid bone & 2 \\
Parietal bone & 5 \\
Occipital bone & 4 \\
Pterygoid plate & 6 \\
\hline
\end{tabular}



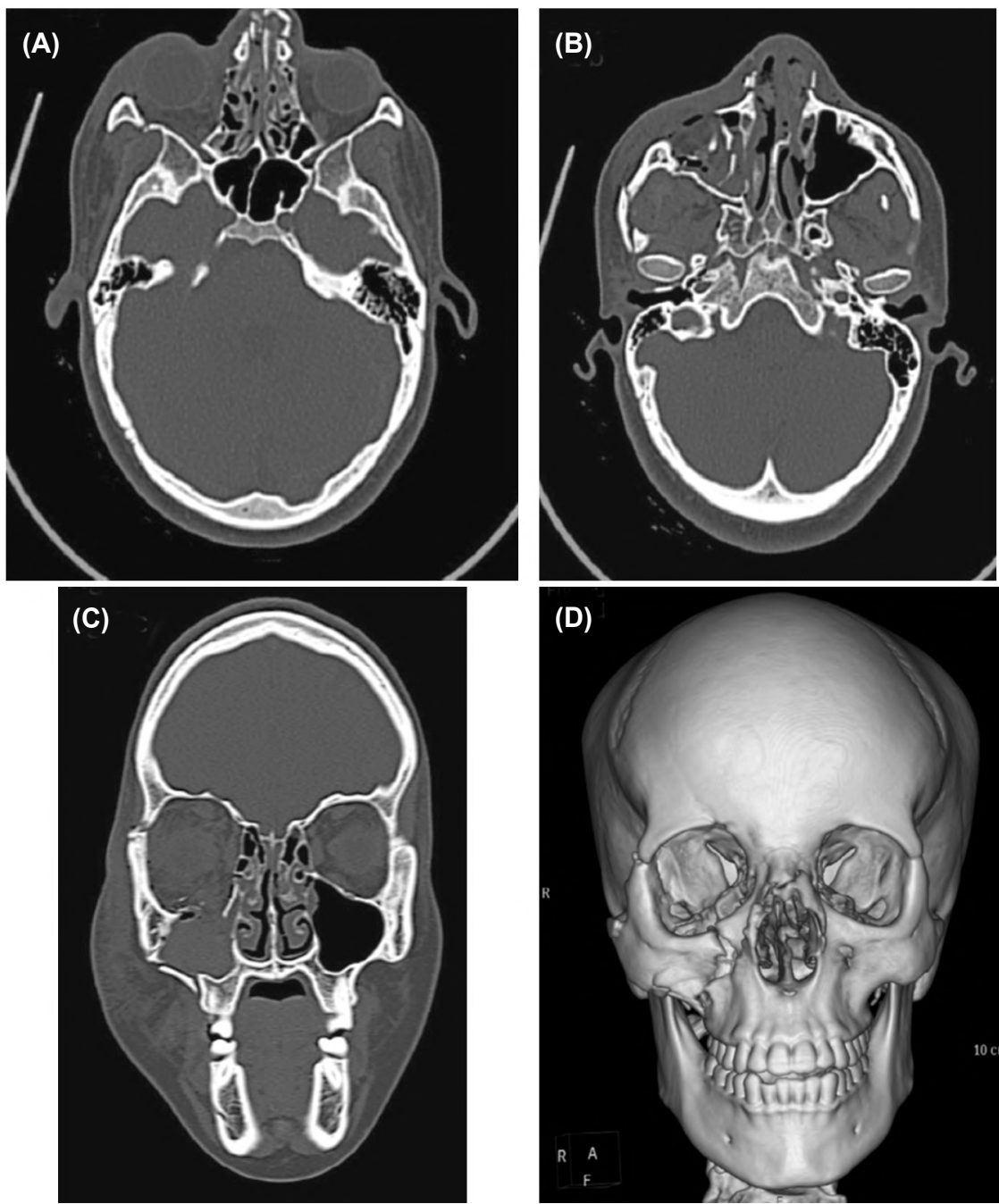

As stated before, the most common fractures were maxilla and maxillary sinus fractures found in 43 cases representing $43 \%$ of cases with combined fractures of the anterior and medial walls were the commonest injuries found in 22 cases (51\% of cases with maxillary fractures) Fig. (2).

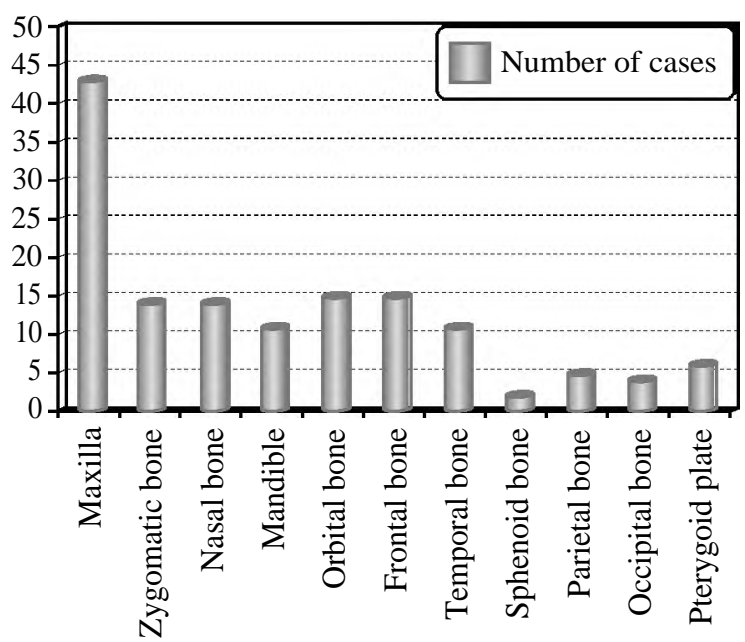

Fig. (2): A bar chart showing classification of maxillofacial fractures according to number of cases in this study.
Fig. (1): A post-traumatic 35 years old male patient. (A) Axial CT images showing right orbital lateral wall and nasal bone fractures. (B) Axial CT images showing right maxillary lateral wall, roof and floor fractures (showing hemosinus and intra-sinus bone fragments) with right zygomatic fracture, nasal bone fracture and subcutanous oedema. (C) Coronal CT images showing right maxillary lateral wall, roof and floor fractures (showing hemosinus and intra-sinus bone fragments) with right orbital lateral wall fracture and subcutanous oedema. (D) 3D reconstructed images CT images showing right maxillary lateral wall, roof and floor fractures with right orbital lateral wall fracture and nasal bone fractures.
Frontal bone fractures were found in 15 cases representing $15 \%$ of total number of patients with type I found in 2 cases, type II in 6 cases, type III in 4 cases, type IV in 2 cases and type $\mathrm{V}$ in only one case. 3D VRT images gave same information of that of the axial and reformatted images yet with inadequate assessment of the fracture extension to the posterior frontal sinus wall or the orbital roof (Table 2).

Table (2): Classification of cases according to type of frontal fractures.

\begin{tabular}{lc}
\hline Type of frontal bone fracture & Number of cases \\
\hline I & 2 \\
II & 6 \\
III & 4 \\
IV & 2 \\
V & 1 \\
\hline
\end{tabular}

Zygomatic bone fractures were found in 14 cases (14\% of cases) with the 3D VRT images giving same findings of that of the axial and reformatted CT images, yet superior to them in assessment of patterns of bone displacements. 
In 15 cases ( $15 \%$ of cases), orbital bone fractures were present with RTA being the commonest cause of injury. Lateral wall followed by medial wall fractures were the most commonly encountered fractures. Inferior and medial wall combined fractures impressive of complex blow out fracture was found in only one case Fig. (1). No significant difference was found between 3D VRT findings as well as axial and reformatted images.

Fracture of the nasal bone was found in 14 cases (14\% of cases) mainly resulting from RTA Fig. (1) with the 3D VRT images found to be more informative compared to axial and reformatted images.

Mandibular fractures were seen in 11 cases (11\% of cases), mostly affecting its body in 8 cases (73\% of mandibular fractures).

Only $2 \%$ of cases had fracture of the sphenoid wing, however $11 \%$ of cases showed fracture of the temporal bone, mainly its squamous part.
Le fort fractures were seen in 10 cases $(10 \%$ of cases), the commonest was type II ( 8 cases).

Soft tissue swellings were the associated findings with highest incidence, followed by heamosinus. Other severe injuries were found, mainly pneumocephalus, contusion, sub-arachnoid hemorrhage, sub-dural hemorrhage, epi-dural hemorrhage, and sub-galeal hematoma Figs. $(1,4)$. Axial and reformatted images in soft tissue window were found to be superior to 3D VRT images in their assessment (Table 3).

Table (3): Classification of cases according to associated soft tissue injuries.

\begin{tabular}{lc}
\hline Associated injuries & Number of cases \\
\hline Heamo-sinus & 46 \\
EDH & 22 \\
SDH & 11 \\
SAH & 23 \\
Contusions & 12 \\
Pneumocephalus & 15 \\
Sub-galeal hematoma & 36 \\
\hline
\end{tabular}
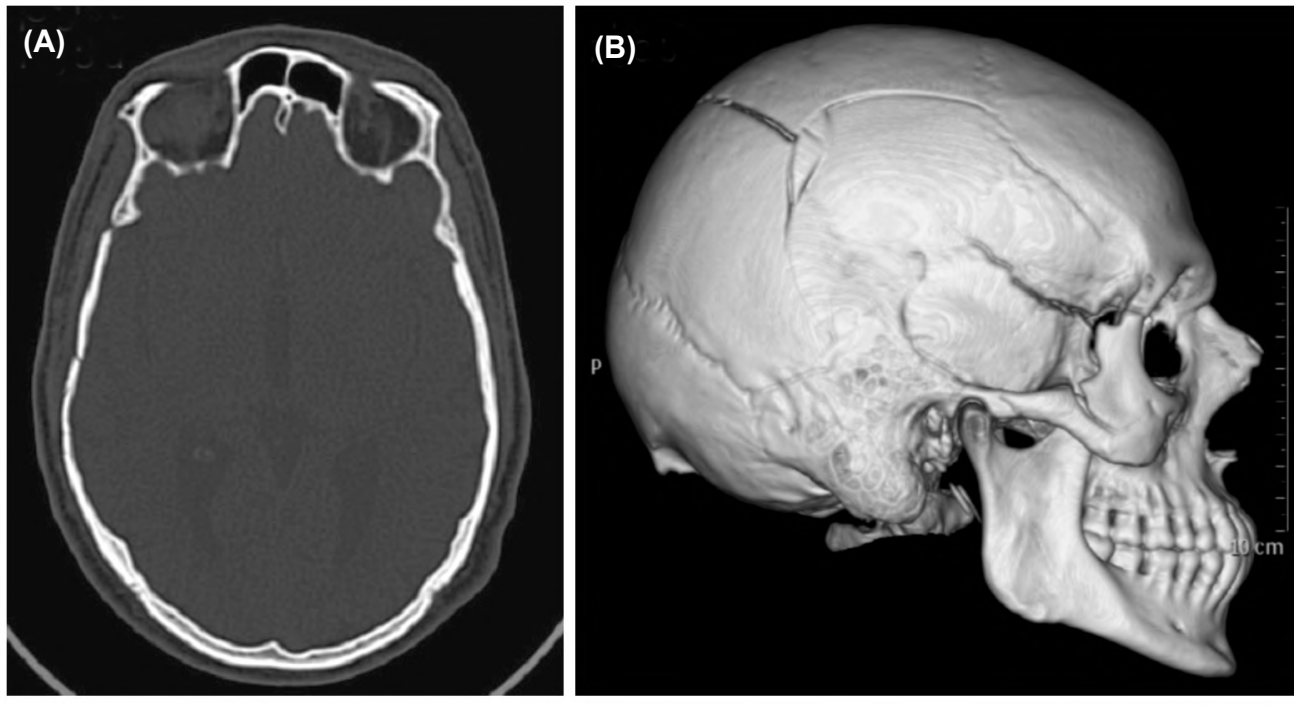

Fig. (3): A post traumatic 46 years old female patient. (A) Axial CT images showing right temporal and parietal bones fractures. (B) 3D reconstructed images CT images showing right temporal and parietal bones fractures as well as right zygomatic fractures.
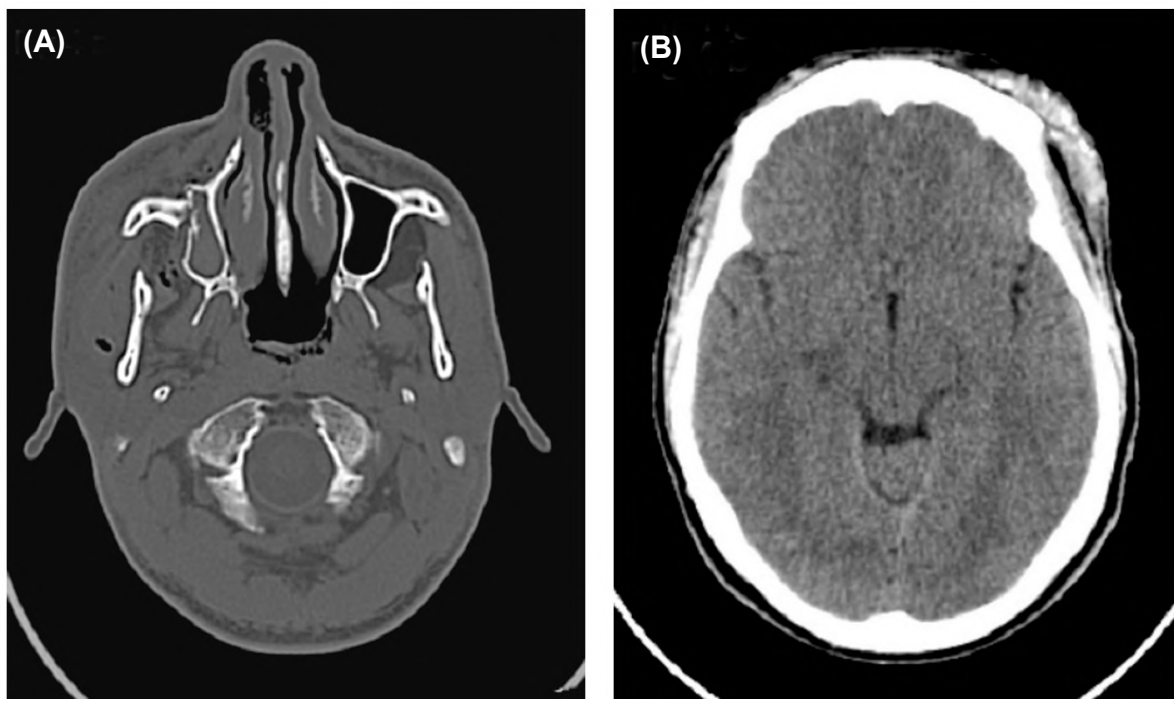

Fig. (4): A post-traumatic 48 years old male patient. (A) Axial CT images showing right maxillary anterior and lateral walls fractures with right hemi-facial subcutaneous oedema. (B) Axial CT images showing left frontal sub-galeal hematoma. 


\section{Discussion}

The face of each individual is a unique ID. Nowadays, the loss of this unique facial configuration as a result of facial injuries is becoming common with increased rate of RTAs. One of the important factors determining the success of treatment of facial fractures is early and correct diagnosis [9]. Maxillofacial fractures are caused by either blunt or penetrating injury or their combination [10].

In our study most of the cases ( 85 cases) of maxillo-facial injuries (85\% of cases) were caused by RTA with 5 cases caused by physical assault representing (5\% of cases) and 10 cases caused by fall from height (10\% of cases). This is consistent with studies that stated that in developing countries, the usual cause of facial injuries is RTA's [11-13] while assault was the commonest cause of these injuries in developed countries [14]. The causes of maxillofacial fractures vary according to social, cultural, and environmental factors [15].

The injuries due to RTA's were found to be more common in males ( 90 cases accounting for $90 \%$ of cases) compared to females (10 cases accounting for $10 \%$ of cases).

In our study maxillary fractures were the commonest type of fractures noted in 43 cases accounting for $43 \%$ of the cases, while mandibular fractures were the commonest type of fractures seen in the studies of Motamedi et al., [14] and Kamulegeya et al., [16]. On the other hand we found that commonest middle third facial region fractures were fractures of the maxilla and maxillary sinus, while it was rare to detect isolated posterior maxillary wall fractures in agreement with Dreizin et al., [17].

Combined anterior and medial wall fractures of the maxillary sinuses were the most common injury in our study (22 cases) accounting for about $51 \%$ of maxillary sinus fractures.

In agreement with Rowe et al., [18], comparison of 3D image to the axial scans in this study revealed that some fractures might be missed by 3D images with maxillary sinus medial wall fracture being the most common one (16\%).

In agreement to our study, Simonds et al. [19] and Ogura et al., [20] stated that TMJ affection might occur with mandibular fractures on the same side.

In this study, orbital bone fracture was detected in 15 cases ( $15 \%$ of cases), mainly due to RTA where lateral wall fracture was the commonest fracture found in 9 cases then there was medial wall in 3 cases followed by roof in 2 cases. Only one case showed both inferior and medial walls fracture impressive of complex blow out fracture. Associated air-fluid level or maxillary sinus fractures is common. This is in agreement with Obuekewe et al., [21] who stated that RTAs was the main cause for most zygomatic complex fractures and the role of VRT is highly significant concerning the assessment of these fractures compared to axial and reformatted images.

The most common isolated bone fractures is nasal bone fracture, in this study, nasal bone fracture was detected in 14 cases with associated bony nasal septum fracture found in 4 of them, this is in agreement to et al., [22] who also noted the efficiency of VRT images in nasal bone fractures.

Frontal bone fractures were found in 15 cases representing $15 \%$ of total number of patients with type II representing the most common type of fracture seen (6 cases). In agreement with Diaconu et al., [23], 3D VRT images gave same information of that of the axial and reformatted images yet with inadequate assessment of the fracture extension to the posterior frontal sinus wall or the orbital roof.

We also agreed with Kaur et al., [24] who stated that $3 \mathrm{D}$ images were superior to axial images in the description of extent in most patients with zygomatic bone fractures.

Prasad et al., [25] agreed with our study in the fact that $3 \mathrm{D}$ reconstruction highly contributed in assessment of patients prior to surgery thus guiding surgical planning in cases with maxillo-facial fractures. The combination of MSCT and 3D volume rendering technique allowed marked improvements in imaging interpretation.

In agreement with Dreizin et al., [17], soft tissue swellings were the associated findings with highest incidence, followed by heamosinus. Axial and reformatted images in soft tissue window were found to be superior to 3D VRT images in their assessment.

\section{Conclusion:}

Maxillo-facial fractures usually occur in complex patterns associated with multiple soft-tissue injuries and complications. Accurate visualization and assessment of facial fractures is very important for proper management. MDCT and 3D images have a great role in the diagnosis and proper assessment of facial trauma with combination of the 
axial thin cut images and 3D reconstructed images to minimize any occult fractures' missing.

\section{References}

1- ROWE L.D., MILLER E. and BRANDT-ZAWADZKI M.: Computed tomography in maxillofacial trauma. Laryngoscope, 91 (5): 745-57, 1981.

2- ALLAREDDY V., ALLAREDDY V. and NALLIAH R.P.: Epidemiology of facial fracture injuries. J. Oral Maxillofac. Surg., 69 (10): 2613-8, 2011.

3- YADAV S.K., MANDAL B.K., KARN A. and SAH A.K. Maxillofacial trauma with head injuries at a tertiary care hospital in Chitwan, Nepal: Clinical, medico-legal, and critical care concerns. Turk. J. Med. Sci., 42 (Sup. 2): 1505-12, 2012.

4- LAINE F.J., CONWAY W.F. and LASKIN D.M.: Radiology of maxillofacial trauma. Curr. Probl. Diagn. Radiol., 22 (4): 145-88, 1993.

5- SALONEN E.M., KOIVIKKO M.P. and KOSKINEN S.K.: Acute facial trauma in falling accidents: MDCT analysis of 500 patients. Emerg. Radiol., 15 (4): 241-7. DOI: $10.1007 / \mathrm{s} 10140008-0717-2,2008$.

6- SOM P.M. and CURTIN H.D.: Head and neck imaging. 5th ed. St. Louis, Mo: Mosby, 2002.

7- SAIGAL K., WINOKUR R.S. and FINDEN S.: Use of three-dimensional computerized tomography reconstruction in complex facial trauma. Facial Plast. Surg., 21 (3): 214-20. 10.1055/s2005-922862, 2005.

8- RHEA J.T. and NOVELLINE R.A.: How to simplify the CT diagnosis of Le Fort fractures. A.J.R. Am. J. Roentgenol., 184 (5): 1700-5. 10.2214/ajr.184.5.01841700, 2005.

9- RAJU SREENIVASA N., PRASHANTH ISHWAR and RUMPA BANERJEE: Department of Radiodiagnosis, Adichunchanagiri Institute of Medical Sciences, Mandya, Karnataka, India. [Role of multislice computed tomography and three-dimensional rendering in the evaluation of maxillofacial injuries (Journal of Oral and Maxillofacial Radiology/Volume 5/Issue 3/September-December 2017).

10- KIESER J., STEPHENSON S., LISTON P.N., TONG D.C. and LANGLEY J.D.: Serious facial fractures in New Zealand from 1979 to 1998. Int. J. Oral Maxillofac. Surg., 31 (2): 206-9.10.1054/ijom.2002.0208, 2002.

11- ADEKEYE E.O.: The pattern of fractures of the facial skeleton in Kaduna, Nigeria. A survey of 1,447 cases Oral Surg. Oral Med. Oral Pathol., 49 (6): 491-5. Doi: 10.1016/0030-4220(80)90068-7, 1980.

12- BOCHLOGYROS P.N.: A retrospective study of 1,521 mandibular fractures. J. Oral Maxillofac. Surg., 43 (8): 597-9, 1985.

13- HAUG R.H., PRATHER J. and INDRESANO A.T.: An epidemiologic survey of facial fractures and concomitant injuries. J. Oral Maxillofac. Surg., 48 (9): 926-32, 1990.

14- MOTAMEDI M.H.: An assessment of maxillofacial fractures: A 5-year study of 237 patients. J. Oral Maxillofac. Surg., 61(1): 61-4. Doi: 10.1053/joms.2003.50049, 2003.

15- KHAN A.A.: A retrospective study of injuries to the maxillofacial skeleton in Harare, Zimbabwe. Br. J. Oral Maxillofac. Surg., 26 (5): 435-9, 1988.

16- KAMULEGEYA A., LAKOR F. and KABENGE K.: Oral maxillofacial fractures seen at a Ugandan tertiary hospital: A six-month prospective study. Clinics (Sao Paulo), 64 (9): 843-8, 2009.

17- DREIZIN D., ARTHUR J. NAM, SILVIU C. DIACONU, MARK P. BERNSTEIN, UTTAM K. BODANAPALLY and FELIPE MUNERA: Multidetector CT of Midfacial Fractures: Classification Systems, Principles of Reduction, and Common Complications. RadioGraphics, 38: 1, 24874, 2018.

18- ROWE S.P., ZINREICH S.J. and FISHMAN E.K.: 3D cinematic rendering of the calvarium, maxillofacial structures, and skull base: Preliminary observations. Br. J. Radiol., Jun. 91 (1086): 20170826, 2018.

19- SIMONDS J.S., WHITLOW C.T. and CHEN M.Y.: Isolated fractures of the posterior maxillary sinus: CT appearance and proposed mechanism. A.J.N.R. Am. J. Neuroradiol., 32 (3): 468-70. Doi: 10.3174/ajnr.A2337, 2011.

20- OGURA I., KANEDA T., MORI S., SEKIYA K. and OGAWA H.: Characterization of mandibular fractures using 64-slice multidetector CT. Dentomaxillofac. Radiol., 41 (5): 392-5. Doi: 10.1259/dmfr/67127210, 2012.

21- OBUEKWE O., OWOTADE F. and OSAIYUWU O. Etiology and pattern of zygomatic complex fractures: A retrospective study. J. Natl. Med. Assoc., 97 (7): 992-6, 2005.

22- BAEK H.J., KIM D.W., RYU J.H. and LEE Y.J.: Identification of Nasal Bone Fractures on Conventional Radiography and Facial CT: Comparison of the Diagnostic Accuracy in Different Imaging Modalities and Analysis of Interobserver Reliability. Iran J. Radiol., 10 (3): 1407. Doi: 10.5812/ iranjradiol.6353, 2013.

23- DIACONU S.C., DREIZIN D., ULUER M., MOSSOP C., GRANT M.P. and NAM A.J.: The validity and reliability of computed tomogra-phy orbital volume measurements. J. Craniomaxillofac. Surg., 45 (9): 1552-7, 2017.

24- KAUR J. and CHOPRA R.: Three dimensional ct reconstruction for the evaluation and surgical planning of mid face fractures: A 100 case study. J. Maxillofac. Oral Surg., 9 (4): 323-8. Doi: 10.1007/s12663-010-0137-1, 2010.

25- PRASAD NATRAJ V., Ashish Khanal Department of Radiodiagnosis, College of Medical Sciences-Teaching Hospital, Bharatpur, Nepal Prasad VN, Khanal A. Computed Tomography evaluation of maxillofacial injuries. JCMS Nepal., 12 (4): 131-6, 2016. 


\section{تقنية تقديم الحجم في الإصابات الصادمة للوجه والفورة والفكين.

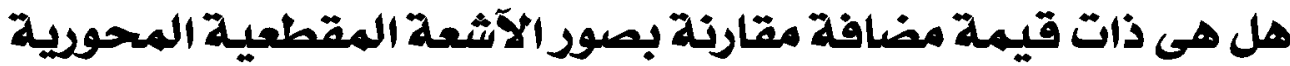

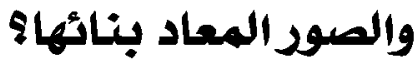

المقدمة: كثيراً ما ينظر إلى كسود الوجه والفكين كنتيجة لحدوث زيادة حوادث المرود على الطرق والمعارك المقار العدوانية. نظراً للتطورات

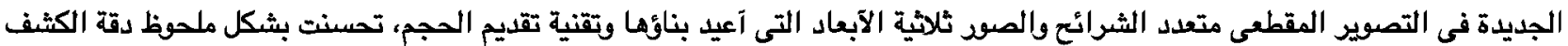
عن الكسو الخفية ونتائج الصدمات الفكية الوجهية.

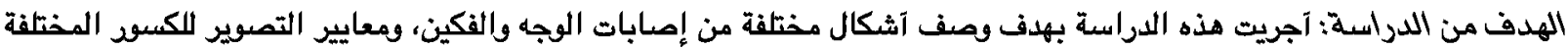

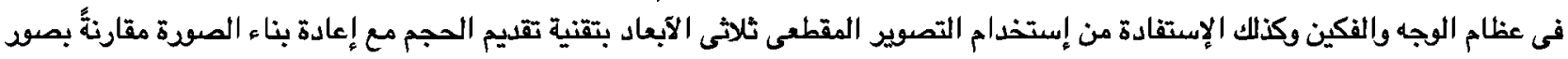
التصوير المقطعى المحوىى.

الوسائل والمرضى: دراسة مستقبلية ل. ـ ا مريض، قادمين إلى قسم الطوارئ مصابين بصدامات وآدلة إكلينيكية توحى بإصابات الوجها

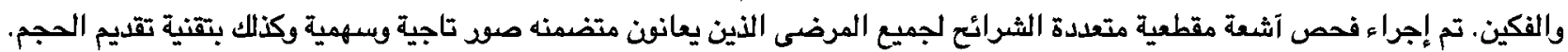

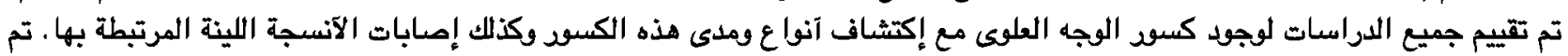
تقييم النتائج التى لم يتم تاكيدها آو تآكيدها بواسطة صود بتقنية تقديم الحجم مقارنة بالنتائج التى عثر عليها بواسطة الصود المحورية.

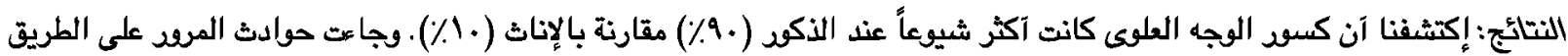

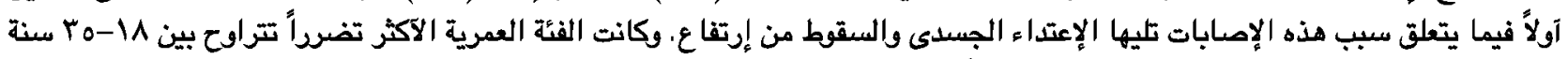

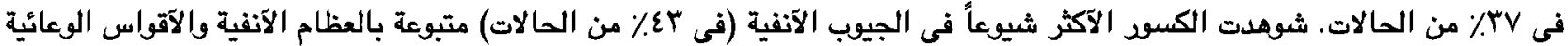

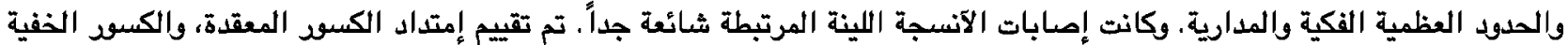

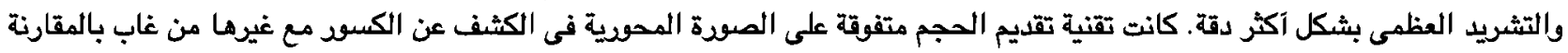
مع النتائج التى توصلت إليها الصود المحورية للآشعة المقطعية.

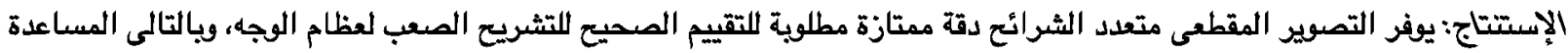

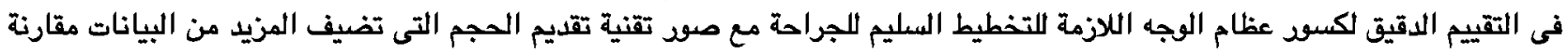
بالصور المحوية وإعادة البناء. 